\title{
Agricultural management and pesticide use reduce the phosphorus uptake capability of beneficial plant symbionts
}

\section{Anna Edlinger}

Agroscope https://orcid.org/0000-0003-3538-2371

Gina Garland

Agroscope

\section{Samiran Banerjee}

Department of Microbiological Sciences, North Dakota State University, Fargo, ND, 58102

\section{Florine Degrune}

University of Applied Sciences and Arts Western Switzerland

\section{Pablo García-Palacios}

Consejo Superior de Investigaciones Científicas https://orcid.org/0000-0002-6367-4761

\section{Sara Hallin}

Swedish University of Agricultural Sciences https://orcid.org/0000-0002-9069-9024

\section{Chantal Herzog}

Agroscope, Agroecology and Environment https://orcid.org/0000-0002-3085-2015

\section{Jan Jansa}

Institute of Microbiology, Czech Academy of Sciences https://orcid.org/0000-0002-0331-1774

\section{Elena Kost}

Agroscope

\section{Fernando Maestre}

Instituto Multidisciplinar para el Estudio del Medio "Ramón Margalef", Universidad de Alicante

\section{David Sánchez Pescador}

12Departamento de Farmacología, Farmacognosia y Botánica

\section{Laurent Philippot}

French National Institute for Agricultural Research

\section{Matthias Rillig}

Free University of Berlin https://orcid.org/0000-0003-3541-7853

\section{Sana Romdhane}

University Bourgogne Franche Comte, INRAE

\section{Aurélien Saghaï}

Swedish University of Agricultural Sciences

https://orcid.org/0000-0002-7069-2159

\section{Aymé Spor}


INRA, Dijon https://orcid.org/0000-0002-4707-9559

\section{Emmanuel Frossard}

Institute of Agricultural Sciences, ETH Zurich

Marcel van der Heijden ( $\nabla$ marcel.vanderheijden@agroscope.admin.ch )

University of Zurich https://orcid.org/0000-0001-7040-1924

\section{Article}

Keywords: Phosphorus acquisition, arbuscular mycorrhizal fungi, agroecosystems, agricultural management, pesticide use

Posted Date: August 26th, 2021

DOl: https://doi.org/10.21203/rs.3.rs-827966/v1

License: (c) (i) This work is licensed under a Creative Commons Attribution 4.0 International License. Read Full License

Version of Record: A version of this preprint was published at Nature Ecology \&amp; Evolution on July 7th, 2022. See the published version at https://doi.org/10.1038/s41559-022-01799-8. 


\section{Abstract}

Phosphorus (P) acquisition is key for global food production. Arbuscular mycorrhizal fungi (AMF) help plants acquire $P$ and are considered key for the design of sustainable agroecosystems. However, how the functioning of AMF varies across agricultural soils and responds to management practices is still unknown. Here, we collected soils from 150 cereal fields and 60 non-cropped grassland sites across Europe, and in a greenhouse experiment, we tested the ability of AMF in these soils to forage for radioisotope-labelled ${ }^{33} \mathrm{P}$ from a hyphal compartment. Hyphal-mediated $\mathrm{P}$ uptake was $64 \%$ higher in noncropped grassland compared to cropland soils. Soil pH and organic carbon best explained the hyphalmediated $\mathrm{P}$ uptake in the grasslands, while the use of fungicide in croplands reduced $\mathrm{P}$ uptake in the croplands by $43 \%$. Our results suggest that land-use intensity and fungicide use are major deterrents to the natural capacity of AMF to contribute to sustainable crop production.

\section{Introduction}

With the global population growing, we need to find ways to promote crop production while minimizing environmental degradation ${ }^{1,2}$. Harnessing the functions provided by species above- and below ground in the agricultural landscape is a promising approach to address both goals, thus paving the way to an ecological intensification of agroecosystems ${ }^{3,4}$.

Arbuscular mycorrhizal fungi (AMF) inhabit the soils of virtually all terrestrial ecosystems and form symbiotic associations with most plants, including agricultural crops ${ }^{5,6}$. Plants deliver assimilates to AMF in return for nutrients, especially phosphorus $(P)$, which AMF acquire through their extensive soil hyphal networks. AMF may supply up to $90 \%$ of the host plant's $P$ requirements, especially in nutrientpoor and undisturbed vegetation $5,7,8$. Therefore, promoting the natural potential of AMF for crop $P$ nutrition could circumvent the adverse environmental effects of high $P$ fertilization ${ }^{9,10}$ and increase $P$ availability in cropping systems with low fertilizer access. The AMF-symbiosis is thus key to improve Puse efficiency and to the design sustainable agroecosystems ${ }^{11-13}$. Nevertheless, the relevance of AMF symbiosis for crop production in agricultural systems is still under debate ${ }^{14-17}$.

The contribution of AMF to plant nutrition might be context-dependent, given that AMF communities are shaped by local environmental conditions ${ }^{18}$ and that the benefits of AMF to plant growth are cultivar dependent ${ }^{19,20}$. Some modern crop cultivars are less efficiently colonized by AMF and have been shown to only benefit from AMF under P limitation ${ }^{21,22}$ likely since crop breeding and selection have not prioritized these symbiotic associations. Apart from this, the abundance and diversity of AMF communities are negatively affected by intensive management practices ${ }^{23-25}$, especially tillage, inorganic fertilization, and pesticide use. Whether changes in AMF communities subsequently impact their ability to acquire $P$ for growing plants is still poorly understood. Until now, broad scale assessments of AMF functioning across different environmental conditions and land use types have not been 
performed, contributing to our lack of understanding of the drivers of hyphal $\mathrm{P}$ acquisition in intensively and extensively managed plant-soil systems.

To address these knowledge gaps, we collected 210 soils originating from cropland fields and noncropped grassland sites across a $3000 \mathrm{~km}$ European north-to-south gradient. Plantago lanceolata was then grown on these soils in a greenhouse experiment in which we measured the capacity of the associated AMF to mediate $P$ uptake from a radioisotope-labelled hyphal compartment (Fig. 1). This allowed us to 1) estimate the capacity of native AMF communities in different soils to provide plants with $P$, and 2) assess the drivers of $P$ uptake by including climatic background, biotic and abiotic soil properties, legacy effects of land use and crop management practices in the analysis. We hypothesized that i) hyphal $\mathrm{P}$ uptake is strongly driven by the large gradient in climate and soil characteristics, ii) hyphal $\mathrm{P}$ uptake is lower in cropland compared to non-cropped grassland soils, and iii) intensive agricultural practices (pesticide use, tillage, and fertilization) negatively impact hyphal mediated $P$ uptake. Ultimately, our research contributes to a better understanding of the main drivers of AMF functioning in agroecosystems, paving the way to harness their natural capacity for supporting crop production.

\section{Methods}

Field sites

In spring 2017 we sampled soils from 150 croplands and 60 non-cropped grassland sites across a NorthSouth gradient in Europe covering Sweden $(n=34)$, Germany $(n=48)$, Switzerland $(n=57)$, France $(n=$ 39), and Spain ( $\mathrm{n}=32)$ (Supplementary Fig. S1). To minimize variation in AMF caused by different crop types, we selected cereal fields planted with wheat (Triticum $s p ., \mathrm{n}=119$ ), or closely related cereals like barley (Hordeum vulgare, $\mathrm{n}=25$ ) and oat (Avena sativa, $\mathrm{n}=6$ ), when wheat fields were not available. Furthermore, we sampled exclusively plots where conventional tillage practices had been performed. Although 26 croplands (17\%) in Switzerland and Southern Germany were organically managed, they did not statistically differ from their neighboring conventional fields in terms of hyphal P uptake (Supplementary Fig. S2), and therefore were kept in the dataset. The non-cropped grassland sites were located in the vicinity of the croplands to cover a similar gradient in soil characteristics. These sites comprised extensively managed grasslands and marginal land (field strips) neighboring the croplands and were characterized by a permanent, predominantly herbaceous plant cover that was not part of a crop rotation. Most of these sites were unfertilized and occasionally mowed, although exact information on fertilization, grazing and mowing was not available for all of the sites. Following the classification by the Eurostat Land Use / Cover Area Frame Survey (LUCAS) ${ }^{26}$, we refer to these plots as grassland sites.

Environmental data and location

To characterize the variation in climate along the sampled gradient, information on mean annual temperature (MAT) and mean annual precipitation (MAP) was extracted from the WorldClim Global 
Climate Data ${ }^{27}$. Aridity information was derived from the CGIAR-CSI database, where it is expressed as a function of MAP over the mean annual potential evapotranspiration ${ }^{28}$. In line with recent studies ${ }^{29,30}$, we subtracted the aridity index from 1 , to define aridity in our analyses such that higher aridity values indicate drier conditions. Additionally, the location of the fields along the gradients was described by the geographic distance from the S-W-most sampling site using the haversine formula ${ }^{31}$.

\section{Management practices}

To determine the legacy effects of crop management on hyphal activity in the croplands, farmers and field managers provided information on management practices including fertilizer and pesticide use, tillage intensity (all during 2016, one year before sampling), as well as the crop rotational diversity and the duration of crop cover (during ten years before sampling) (Table 1B). Fertilization intensity was assessed using the total amount of mineral $\mathrm{N}$ (ammonium and nitrate) applied through organic and/or mineral fertilization. Organic fertilization was additionally included as a binary variable in the analyses. The use of fungicides, herbicides and insecticides was summarized with the number of their respective application events. For fungicides, we further took into consideration the total amount and number of different active compounds added per hectare. However, these parameters were strongly linked to each other. Therefore, we focused our analysis on the number of application events, since they had the strongest correlation with our output variable of interest (Supplementary Table S1). Tillage intensity was estimated by averaging the number and maximum depth of tillage events (after normalization). For the crop rotations (see Appendix A for more details), we calculated the proportion of time with plant cover and the crop diversity at each site according to a Shannon diversity index ${ }^{32}$.

Soil sampling

To reduce variation between sites related to crop growth stage, all soils were collected during wheat flowering at each site (ranging from May in Spain to August in Sweden). At each site, eight soil samples were taken in a circular pattern within a $10 \mathrm{~m}$ radius using a five $\mathrm{cm}$ diameter auger and to a depth of 20 $\mathrm{cm}$. Three of the soil cores were kept intact and stored at $4^{\circ} \mathrm{C}$ before preparing them for the compartment experiment. The other soil cores were homogenized and sieved to 2-mm. A portion of this soil was airdried for further processing of soil physical and chemical analyses. Soil texture, calcium carbonate $\left(\mathrm{CaCO}_{3}\right), \mathrm{pH}$, soil organic $\mathrm{C}(\mathrm{SOC})$, total nitrogen $(\mathrm{N})$ and total phosphorus $(\mathrm{P})$ were measured on the dried samples. Available phosphorus (Olsen $\mathrm{P}$ ), and the microbial biomass $\mathrm{C}$ were measured on fresh soil samples within a few weeks after sampling. All above mentioned soil properties were measured following the Swiss standard protocols (Swiss federal research stations, 1996).

Soil microbial analyses

To assess the microbial diversity, DNA was extracted from $250 \mathrm{mg}$ of each soil sample (stored at $-19^{\circ} \mathrm{C}$ ) using the DNeasy PowerSoil-htp 96 well DNA isolation kit (Qiagen, France). Microbial diversity was further analyzed as described in Garland et al. (2021) ${ }^{32}$. Briefly, amplicons of bacterial and archaeal 16S 
rRNA genes were generated in two steps following Berry et al. $(2011)^{33}$ in two separate sequence data sets, one for each domain.. The fungal ITS2 region was amplified using the PacBio SMRT Sequencing platform (Pacific Biosciences, CA) with the primers ITS1f (CTTGGTCATTTAGAGGAAGTAA) and ITS4 (TCCTCCGCTTATTGATATGC) targeting the entire ITS region ( $630 \mathrm{bp})^{34,35}$. Cercozoa diversity was estimated with a two-step PCR to amplify a fragment (c. $350 \mathrm{bp}$ ) of the V4 region of the 18S rRNA gene using the primers sets designed by Fiore-Donne et al. $(2018)^{36}$ for the specific amplification of cercozoa. Finally, alpha diversity of soil bacterial, fungal, archaeal, and cercozoan communities was assessed using the Shannon-Weaver index of diversity.

AMF compartment system

To assess AMF hyphal ${ }^{33} \mathrm{P}$ transfer rates and hyphal activity in the collected field soils, we conducted an experiment starting in March 2018 using a compartment setup (Fig. 1) following, amongst others, Schweiger et a. (1999) ${ }^{37}$ and Svenningsen et al. $(2018)^{38}$. We used the radioisotope ${ }^{33} \mathrm{P}$ to trace $\mathrm{P}$ transport by fungal hyphae to Plantago lanceolata plants. To this end, the plant zone (compartment a; Fig. 1) of the compartment system was separated with a mesh (pore size $40 \mu \mathrm{m}$ ), hindering the plant roots to penetrate the hyphal zone (compartments $b$ and $c$; Fig. 1). The buffer zone (compartment b; Fig. 1) had the purpose to minimize possible diffusion of ${ }^{33} \mathrm{P}$ injected into compartment c (Fig. 1) from entering the plant zone ${ }^{37}$.

The different field soils were filled into the compartments $a$ and $b$ to a total volume of $850 \mathrm{~cm}^{3}$. To do so, three of the collected soil cores, which were kept intact and stored at $4^{\circ} \mathrm{C}$, were homogenized by gently removing stones and residues larger than $8 \mathrm{~mm}$. A subsample was taken to assess the water content, available $\mathrm{N}$ and the exact weight of the soil at the start of the experiment. Furthermore, seven negative control pots were implemented using X-ray sterilized soils originating from four croplands and three grassland sites representing a range of soil properties $\left(\mathrm{pH} 5.97-8.03\right.$, Olsen $\mathrm{P} 1.8-118 \mathrm{mg} \mathrm{g}^{-1}$, Sand $18.34-33.53 \%$ ), to verify that no or little ${ }^{33} \mathrm{P}$ would be found in plants when no AMF are present (Fig. 2). Very small amounts of label were detected in the sterilized control pots demonstrating that fungal hyphae present in the field soil, rather than fine roots, mass flow, or microbial propagules in the greenhouse air, were responsible for the recorded ${ }^{33} \mathrm{P}$ uptake by plants. Additionally, assessments of AMF root colonization and AMF abundance in the hyphal compartment c (Fig. 1) in a subset of the soils $(n=36$; methods outlined in Appendix B) showed that roots in pots filled with unsterile field soils were strongly colonized by AMF and that AMF accessed the hyphal compartment $\mathrm{c}$ in the respective pots. In contrast, the sterilized control pots had little AMF root colonization and AMF abundance in the hyphal compartments was negligible (Supplementary Fig. S3 A and C).

The pots were watered to $60 \%$ of the soils' water-holding capacity and the soil volume was adjusted after two days if necessary. The hyphal compartment c (Fig. 1), into which the ${ }^{33} \mathrm{P}$ was injected later, was filled with a standardized, $\mathrm{X}$-ray sterilized soil (58 g dry mass) from an extensively managed grassland soil at 
Agroscope Reckenholz, Zurich, Switzerland. Using a standardized soil in compartment c allowed for a similar sorption of ${ }^{33} \mathrm{P}$ at the injection spot, enabling us to focus our analyses on the hyphal activity solely, rather than the soils' $\mathrm{P}$ sorption capacity, which is highly variable across soils ${ }^{39}$.

After three days of pre-incubation, five sterilized and pre-germinated seeds of Plantago lanceolata were planted in compartment a of each pot. Plantago lanceolata was selected as the model plant in this experiment because the plant usually forms a strong symbiosis with AMF and it is present across the surveyed European gradient and grows well in soils like those used in our experiment ${ }^{23,40}$. To ensure a homogenous plant density, the seedlings were reduced to three individuals per pot after one week. The pots were arranged randomly in the greenhouse. In the following 12 weeks of growth, the plants were watered three times a week to maintain a comparable water level ranging between 60 and $70 \%$ of the individual soil's water holding capacity. Every second week the pots were newly randomized. The temperature adjustments of the greenhouse were between 16 to $18^{\circ} \mathrm{C}$ at night and between 19 and $21^{\circ} \mathrm{C}$ during daytime, at a humidity around $70 \%$ water vapor saturation. Daytime was set at 16 hours with 30 klx lighting.

Plant growth, ${ }^{33} \mathrm{P}$-injection, and analyses

After 10 weeks of plant growth, $200 \mu$ l of a carrier-free ${ }^{33} \mathrm{PO}_{4}{ }^{3-}$-solution $\left(2333 \mathrm{kBq} \mathrm{ml}^{-1}\right)$ were injected at three different locations within compartment $c$ at a depth of $3-4 \mathrm{~cm}$ using a $200 \mu$ pipette. The experiment was terminated with the harvest of Plantago shoots 12 days after ${ }^{33} \mathrm{P}$ injection, and 12 weeks after planting. The shoots were cut above the soil surface and placed in the oven at $60^{\circ} \mathrm{C}$ for 48 hours. After assessment of the dry shoot biomass, the samples were milled and used for determination of $\mathrm{P}$ and $\mathrm{N}$ contained in shoots. Total plant $\mathrm{N}$ was measured with an elemental analyzer (Vario Pyro Cube, Elementar $\mathrm{GmbH}$, Hanau, Germany). Incinerated samples were microwave-digested with nitric acid ${ }^{41}$. The $\mathrm{P}$ concentration in the extract was then determined colorimetrically using malachite green ${ }^{42}$ and the activity of ${ }^{33} \mathrm{P}$ with liquid scintillation counting (TRI-CARB 2500 TR, liquid scintillation analyzer, Packard Instruments, Meriden, CT) ${ }^{43}$. The measured disintegrations per minute were corrected for the background activity, the time point of measurement and the counting efficiency to account for chemical and color quenching.

Finally, the relative amount of ${ }^{33} \mathrm{P}$, which was recovered in the shoot material after transfer via AMF hyphae from the initially injected pool, i.e., the recovery rate, was calculated using equation (1).

\section{Recovery rate $(\%)=\frac{r(B q) * 100}{R(B q)}$}

Eq. (1)

Where $r$ is the activity of ${ }^{33} \mathrm{P}$ in each sample (Bq g ${ }^{-1}$ shoots) multiplied by the total shoot weight per pot $(\mathrm{g})$, and $R$ refers to the total injected radioactivity $(\mathrm{Bq})$. This recovery rate was then used as an estimate 
for the capacity of AMF to transfer P to growing plants, which we refer to as "hyphal P transfer" in this study.

Statistical analysis

Statistical analyses were performed using the software $R$, version 3.6.0 ${ }^{44}$. Individual missing values in the explanatory variables ( $1.04 \%$ of all investigated predictor values) were replaced with the median value of the respective land use type and country. Differences between land use systems (i.e., cropland and grassland soils) were assessed using a Wilcoxon rank test. For all correlations (i.e., between the different predictors and output variables) a Spearman rank correlation was applied. To assess the most important drivers of hyphal activity within the two land use systems, we performed a three-step model selection approach. First, we selected a wide range of available environmental and management data, under the condition that there is no strong co-correlation between the distinct variables. To do so, we scanned the correlations between all variables (Supplementary Tables S2 \& S3) and reduced variables that were strongly correlated (i.e., Spearman rank correlation coefficient $\rho>0.8$ ). This approach resulted in a pool of 15 predictors used to explain variation in the grassland soils and 25 for the cropland soils. To better describe variation in the cropland soils, the latter also included nine predictors describing management practices (tillage, fertilization, pesticide use, crop diversity, crop cover). The choice of final variables is indicated in the Supplementary Tables S2 and S3, and all used predictors with corresponding units are shown in Table 1. The second step of the model selection involved a multi-model inference approach using the R package $g /$ multi (version 1.0.8) ${ }^{45}$, resulting in a high number of possible linear models, ranked by the Akaine Information criterion (AICC). Using the best model, we explored whether model residuals were normally distributed and applied transformations to the data when needed. Logarithmic transformations were applied to the soil N:P ratio, Nmin:Pmin ratio, and plant N:P ratio, due to their nonnormal distribution. Moreover, the hyphal $\mathrm{P}$ transfer rates were log-transformed for analyses focusing on the grassland systems. In the last step, the best models that fell within an AIC range of 2 were averaged to obtain a conservative estimate and relative importance of the most important predictors following Cade (2015) ${ }^{46}$ using the MuMin package (version 1.43.17) ${ }^{47}$. We used $\triangle$ AIC values to compute the Akaike weight (wi) of each of the selected models, and wi was used to compute a weighted-average model ${ }^{48}$. The relative importance of each predictor was estimated taking all of the models into consideration as the sum of the weights/probabilities for the models in which the variable appears.

The relationships between the most important predictors and the hyphal $\mathrm{P}$ transfer were examined. Variables were transformed, if necessary, to reach a normal distribution of model error and residuals. Furthermore, we compared linear, polynomial (2nd order) and logarithmic functions and, eventually, showed the best-fitting functions (highest $\mathrm{R}^{2}$ ). For pair-wise comparisons between grassland and cropland soils, Wilcoxon rank test was used. For comparisons of more than two groups, a Kruskal-Wallis test followed by Dunn's test was applied to identify which groups are different.

\section{Results}


Effect of land use on hyphal P transfer and soil properties

The recovery of ${ }^{33} \mathrm{P}$ was $64 \%$ higher in pots filled with soils from grassland sites compared to the soils from croplands $(p<0.001$; Fig. 2$)$. There was a large variation in hyphal $P$ transfer in both systems (1.07$17.6 \%$ in grassland soils; $0.003-14.2 \%$ in cropland soils), which was paralleled by significant biotic and abiotic differences between the soils originating from the grassland and cropland systems (Table 1A). Especially the differences in microbial biomass C (-41\% in cropland soils) and available soil $\mathrm{P}$ (Olsen $\mathrm{P},+$ $60 \%$ in cropland soils) were striking and these factors correlated positively and negatively, respectively, with ${ }^{33} \mathrm{P}$ uptake, when considering the whole dataset (Table 1A, Supplementary Fig. S4). Among the management factors considered in croplands, the number of fungicide application events showed the strongest correlation with hyphal P transfer (Table 1B).

We assessed whether the observed difference in hyphal $\mathrm{P}$ transfer in the two land use systems has implications for plant nutrition. We found that plant growth and total $P$ uptake did not differ between land use systems (Fig. 2B and C), despite the greater $\mathrm{P}$ availability in cropland soils and a strong link between available soil $P$ and total $P$ uptake $\left(R^{2}=0.404, p<0.001\right.$; Supplementary Fig. S5 B). Neither plant growth, total $\mathrm{P}$ uptake, nor the plant $\mathrm{N}: \mathrm{P}$ ratio correlated significantly with the hyphal ${ }^{33} \mathrm{P}$ transfer when considering both cropland and grassland together (Supplementary Table S4). However, while hyphal ${ }^{33} \mathrm{P}$ transfer increased with increasing plant N:P ratios in grassland soils (Supplementary Fig. S6 A), there was a weak negative correlation in cropland soils (Supplementary Fig. S6 B). 
Table 1

A. Mean values of climatic and edaphic factors ( \pm standard error) in soils from croplands and grassland sites used in this experiment $(n=210)$. Differences between land use types were assessed using Wilcoxon's rank test. B. The range (min. - max.) and mean values ( \pm standard error) of crop management predictors, applying only to the cropland sites $(n=150)$. The last column $(\mathbf{A}$ and $\mathbf{B})$ shows the Spearman rank correlation coefficient of all variables with the ${ }^{33} \mathrm{p}$ recovery with $p$-values in brackets. Significant $(p<$ $0.05)$ differences and correlations are highlighted in bold.

\begin{tabular}{|c|c|c|c|c|c|}
\hline \multirow[b]{2}{*}{ A } & \multirow[b]{2}{*}{ Unit } & \multicolumn{2}{|c|}{ Mean ( \pm SEM) } & \multirow{2}{*}{$\begin{array}{l}\text { p-value (Wilcoxon's } \\
\text { rank test) }\end{array}$} & \multirow{2}{*}{$\begin{array}{l}\text { Correlation with }{ }^{33} \mathrm{P} \\
\text { recovery }\end{array}$} \\
\hline & & Grassland & Cropland & & \\
\hline Aridity & unitless & $\begin{array}{l}0.10( \pm \\
0.05)\end{array}$ & $\begin{array}{l}0.11( \pm \\
0.03)\end{array}$ & 0.674 & $-0.13(0.069)$ \\
\hline $\begin{array}{l}\text { Annual } \\
\text { temperature }\end{array}$ & ${ }^{\circ} \mathrm{C}$ & $\begin{array}{l}9.77( \pm \\
0.36)\end{array}$ & $\begin{array}{l}9.18( \pm \\
0.25)\end{array}$ & 0.171 & $0.04(0.601)$ \\
\hline Clay & $\%$ & $\begin{array}{l}27.3( \pm \\
1.45)\end{array}$ & $\begin{array}{l}28.2( \pm \\
0.97)\end{array}$ & 0.771 & $0.13(0.056)$ \\
\hline Silt & $\%$ & $\begin{array}{l}33.3( \pm \\
1.66)\end{array}$ & $\begin{array}{l}39.5( \pm \\
0.96)\end{array}$ & 0.004 & $0.01(0.932)$ \\
\hline $\mathrm{pH}$ & unitless & $\begin{array}{l}6.86( \pm \\
0.10)\end{array}$ & $\begin{array}{l}7.11( \pm \\
0.06)\end{array}$ & 0.045 & $0.17(0.017)$ \\
\hline Nmin & $\mathrm{mg} \mathrm{g}^{-1}$ & $\begin{array}{l}14.5( \pm \\
1.11)\end{array}$ & $\begin{array}{l}15.1( \pm \\
0.80)\end{array}$ & 0.797 & $-0.09(0.209)$ \\
\hline Olsen-P & $\mathrm{mg} \mathrm{g}^{-1}$ & $\begin{array}{l}23.9( \pm \\
2.44)\end{array}$ & $\begin{array}{l}38.1( \pm \\
2.06)\end{array}$ & $<0.001$ & $-0.26(0.000)$ \\
\hline Soil C:N & $\mathrm{g} \mathrm{g}^{-1}$ & $\begin{array}{l}8.64( \pm \\
0.32)\end{array}$ & $\begin{array}{l}8.22( \pm \\
0.17)\end{array}$ & 0.262 & $-0.07(0.313)$ \\
\hline Soil N:P & $\mathrm{g} \mathrm{g}^{-1}$ & $\begin{array}{l}0.61( \pm \\
0.58)\end{array}$ & $\begin{array}{l}0.03( \pm \\
0.00)\end{array}$ & 0.007 & $0.18(0.008)$ \\
\hline Soil Nmin:Pmin & $\mathrm{g} \mathrm{g}^{-1}$ & $\begin{array}{l}1.56( \pm \\
0.33)\end{array}$ & $\begin{array}{l}0.71( \pm \\
0.10)\end{array}$ & $<0.001$ & $0.18(0.008)$ \\
\hline soc & $\mathrm{mg} \mathrm{g}^{-1}$ & $\begin{array}{l}20.2( \pm \\
1.53)\end{array}$ & $\begin{array}{l}15.1( \pm \\
0.56)\end{array}$ & 0.003 & $0.17(0.011)$ \\
\hline $\begin{array}{l}\text { Microbial } \\
\text { biomass C }\end{array}$ & $\mathrm{mg} \mathrm{g}^{-1}$ & $\begin{array}{l}0.75( \pm \\
0.05)\end{array}$ & $\begin{array}{l}0.44( \pm \\
0.02)\end{array}$ & $<0.001$ & $0.33(0.000)$ \\
\hline $\begin{array}{l}\text { Soil bacteria } \\
\text { Shannon }\end{array}$ & index & $\begin{array}{l}9.73( \pm \\
0.03)\end{array}$ & $\begin{array}{l}9.89( \pm \\
0.02)\end{array}$ & $<0.001$ & $-0.18(0.009)$ \\
\hline $\begin{array}{l}\text { Soil fungi } \\
\text { Shannon }\end{array}$ & index & $\begin{array}{l}3.79( \pm \\
0.06)\end{array}$ & $\begin{array}{l}3.44( \pm \\
0.04)\end{array}$ & $<0.001$ & $0.19(0.006)$ \\
\hline $\begin{array}{l}\text { Soil cercozoa } \\
\text { Shannon }\end{array}$ & index & $\begin{array}{l}4.93( \pm \\
0.03)\end{array}$ & $\begin{array}{l}4.97( \pm \\
0.02)\end{array}$ & 0.558 & $-0.08(0.260)$ \\
\hline
\end{tabular}




\begin{tabular}{|c|c|c|c|c|c|}
\hline \multirow[b]{2}{*}{ A } & \multirow[b]{2}{*}{ Unit } & \multicolumn{2}{|c|}{ Mean ( \pm SEM) } & \multirow{2}{*}{$\begin{array}{l}\text { p-value (Wilcoxon's } \\
\text { rank test) }\end{array}$} & \multirow{2}{*}{$\begin{array}{l}\text { Correlation with }{ }^{33} \mathrm{P} \\
\text { recovery }\end{array}$} \\
\hline & & Grassland & Cropland & & \\
\hline $\begin{array}{l}\text { Soil archaea } \\
\text { Shannon }\end{array}$ & index & $\begin{array}{l}1.98( \pm \\
0.04)\end{array}$ & $\begin{array}{l}2.06( \pm \\
0.03)\end{array}$ & 0.209 & $0.00(0.983)$ \\
\hline B & Unit & $\begin{array}{l}\text { Min. } \\
\text { value }\end{array}$ & $\begin{array}{l}\text { Max. } \\
\text { value }\end{array}$ & Mean $( \pm$ SEM) & $\begin{array}{l}\text { Correlation with }{ }^{33} \mathrm{P} \\
\text { recovery }\end{array}$ \\
\hline $\begin{array}{l}\text { Organic } \\
\text { fertilization }\end{array}$ & binary & 0 & 1 & $0.36( \pm 0.04)$ & $0.11(0.177)$ \\
\hline Crop cover & index & 0.26 & 1 & $0.79( \pm 0.01)$ & $0.11(0.194)$ \\
\hline Crop Shannon & index & 0 & 2.70 & $1.38( \pm 0.05)$ & $0.14(0.077)$ \\
\hline $\begin{array}{l}\text { Tillage } \\
\text { intensity }^{1}\end{array}$ & index & 0 & 1 & $0.65( \pm 0.01)$ & $0.19(0.020)$ \\
\hline Fertilizer Nmin & $\mathrm{g} \mathrm{m}^{-2}$ & 0 & 31.7 & $13.0( \pm 0.55)$ & $-0.19(0.017)$ \\
\hline $\begin{array}{l}\text { Fungicide } \\
\text { application }^{2}\end{array}$ & $\begin{array}{l}\text { no. of } \\
\text { events }\end{array}$ & 0 & 3 & $0.77( \pm 0.08)$ & $-0.29(0.000)$ \\
\hline $\begin{array}{l}\text { Herbicide } \\
\text { application }\end{array}$ & $\begin{array}{l}\text { no. of } \\
\text { events }\end{array}$ & 0 & 6 & $1.20( \pm 0.09)$ & $-0.13(0.104)$ \\
\hline $\begin{array}{l}\text { Insecticide } \\
\text { application }\end{array}$ & $\begin{array}{l}\text { no. of } \\
\text { events }\end{array}$ & 0 & 1 & $0.12( \pm 0.03)$ & $0.00(0.995)$ \\
\hline \multicolumn{6}{|c|}{${ }^{1}$ Consisting of the number of tillage events $(0-6)$ and the maximum tillage depth $(0-35 \mathrm{~cm})$} \\
\hline
\end{tabular}

\section{Drivers of hyphal P uptake in cropland vs. grassland soils}

Different predictors explained variation in ${ }^{33} \mathrm{P}$ recovery in cropland and non-cropped grassland soils (Fig. 3). In grassland soils, the most prominent and significant predictors were soil $\mathrm{pH}$, followed by available $\mathrm{P}$, aridity, and SOC (Fig. 3A, Supplementary Table S5 A). These four factors explained most variation in the model selection approach and explained $48 \%$ of the variance in ${ }^{33} \mathrm{P}$ recovery (Supplementary Table S5 B). The strong correlation with soil $\mathrm{pH}$ and available $\mathrm{P}$ could also be observed using simple linear regression (Fig. 4).

Relative to grassland soils, less variation in hyphal ${ }^{33} \mathrm{P}$ recovery could be explained in the case of cropland soils ( $\mathrm{R}^{2}$ adj. $=0.18$, Supplementary Table S6 B) despite the larger number of observations and 
the inclusion of various crop management predictors used in these soils (Supplementary Table S3). Nevertheless, soil pH also played a role in the cropland soils, as well as the crop rotational diversity (Fig. 3B). The most important predictor for hyphal ${ }^{33} \mathrm{P}$ uptake was the number of fungicide application events during one year before sampling the soils from the fields (Figs. 3B and 5, Supplementary Table S6 A). ${ }^{33} \mathrm{P}$ uptake in soils without fungicide application was, on average, 2.3 higher compared to soils that received three fungicide applications. Multiple comparison analysis supported this observation, revealing that ${ }^{33} \mathrm{P}$ recovery rates significantly decreased with an increasing number of application events (Fig. 5), paralleling the results from simple linear and quantile regression analysis (Supplementary Fig. S7).

\section{Discussion}

Lower hyphal P transfer in cropland vs. grassland soils

This study demonstrated that AMF communities from non-cropped grassland sites are generally more active and transfer higher amounts of $\mathrm{P}$ to host plants compared to AMF communities from cropland soils. AMF in extensively managed or undisturbed soils are usually more abundant and diverse compared to intensively managed cropland soils that receive substantial amounts of fertilizers and pesticides 24,25,49-53. However, the functional implications of such differences have not been investigated previously. Our observation, stemming from a vast diversity of different soil and climatic characteristics at a broad spatial scale, suggests that the capacity of AMF to support plant nutrition remains underexploited in European croplands. This sheds new light on the debate about the relevance of AMF in crop production ${ }^{54}$.

Various mechanisms could explain the observed differences in AMF functioning between cropland and grassland soils. First, a range of studies showed that management practices associated with intensive land use, including soil tillage, pesticide and fertilizer use, reduce AMF abundance, spore abundance, AMF diversity and alter AMF community composition ${ }^{55,56}$. Additionally, management effects can be indirectly linked with AMF-symbiosis through alterations of soil properties, such as available soil $\mathrm{P}^{25}$. Fertilizer inputs increase plant available $\mathrm{P}$ in the soil, especially in soils with a low $\mathrm{P}$ sorption capacity ${ }^{57}$. High levels of available soil P, often accompanied by low soil N:P ratios were shown to inhibit AMF root colonization and decrease the AMF's relative contribution to plant $\mathrm{P}$ nutrition ${ }^{58-60}$. In accordance with these previous findings, we observed that AMF hyphal $P$ transfer was negatively associated with available soil P levels (Table 1A, Supplementary Fig. S4 B), which were on average $60 \%$ higher in the cropland soils.

We identified several biotic soil properties associated with the differential hyphal $\mathrm{P}$ uptake activity in the two land use types. Interestingly, microbial biomass, which was significantly higher in the grassland soils, correlated positively with hyphal $P$ transfer (Table 1A). This suggests that hyphal $P$ transfer is affected by intensive land-use to a similar extent as the bulk of microbes, which have been shown to be sensitive 
indicators for land-use change ${ }^{61-63}$. AMF are estimated to contribute to $20-30 \%$ of the total soil microbial biomass ${ }^{64}$ and it is likely that the positive link between ${ }^{33} \mathrm{P}$ recovery and microbial biomass is connected to AMF, especially because various studies showed that mycorrhizal hyphal density can correlate strongly with hyphal P uptake $37,38,65$. However, although these earlier studies demonstrated that AMF are the main actors in the transfer of $\mathrm{P}$ from hyphal compartments to plants, the possibility that other organisms (e.g., non-mycorrhizal hyphae) contribute to the transfer of $\mathrm{P}$ to the root zone cannot be excluded. Apart from this, bacteria might facilitate or suppress AMF activity in the soil ${ }^{38}$. Finally, it needs to be noted that $P$ uptake efficiency via hyphal networks depends on the distinct functional traits, activity, and foraging strategies of individual strains of $A M F$ 7,43,66,67 and such aspects need more attention in future work. While we could not make these connections in this present study, further studies should investigate whether specific microbial groups that are affected by intensive management, influence the ability of AMF to acquire $P$.

Soil pH and available $\mathrm{P}$ drive hyphal $\mathrm{P}$ transfer in grassland soils

Using a multi-model inference approach, we were able to identify the main drivers of AMF hyphal P transfer to growing plants. In grassland soils, we found that much of the observed variation in $\mathrm{P}$ uptake could be explained by soil pH, available P, SOC content and climatic factors (e.g., aridity). These results are in line with other studies demonstrating that these factors influence AMF abundance, colonization, and activity ${ }^{38,58,68-70}$.

Our results suggest that plant available $\mathrm{P}$ is a major driver of hyphal $\mathrm{P}$ transfer in grassland soils (Fig. 3B), corresponding to the well-accepted idea that AMF-symbiosis is promoted under nutrient poor conditions ${ }^{59}$. Additionally, our results suggest a suppression of hyphal ${ }^{33} \mathrm{P}$ transfer with decreasing $\mathrm{pH}$, emphasizing the crucial role of soil pH for AMF activity, abundance, community structure as well as the occurrence of AMF host plants ${ }^{38,49,71-74}$. Van aarle et al. $(2002)^{68}$ found reduced growth and activity of the AMF extraradical mycelium in low pH substrates, arguing that AMF are directly stressed by acidic environments. However, it is possible that indirect effects of $\mathrm{pH}$ on the activity of the AMF extraradical mycelium through interactions with other microbiota might be an even more important mechanism behind the suppressiveness of low $\mathrm{pH}$ soils ${ }^{38}$.

Apart from the major importance of soil abiotic factors, our results indicated that increasing aridity decreased hyphal $\mathrm{P}$ transfer in grassland systems. Although we did not manipulate water availability directly and observed only the legacy effects of aridity, our observation parallels various studies that determined direct negative effects of drought on AMF abundance and extraradical hyphae ${ }^{69,70}$. Additionally, plant communities, $\mathrm{C}$ inputs and SOC might be influenced by aridity, resulting in indirect effects on AMF, possibly due to reduced net photosynthesis and energy supply to AMF under waterlimited conditions ${ }^{75}$, corroborating the positive relationship between ${ }^{33} \mathrm{P}$ uptake and $\mathrm{SOC}$ observed in this present study. Ultimately, these results suggest that the goals of promoting $\mathrm{C}$ sequestration and 
improving plant $P$ nutrition through AMF go hand in hand, at least in non-cropped systems where SOC is generally higher (Table 1A).

Fungicide application reduces the ability of AMF to acquire $\mathrm{P}$ in croplands

While a considerable amount of variation in hyphal ${ }^{33} \mathrm{P}$ uptake in grassland soils was explained by soil $\mathrm{pH}$ and $\mathrm{P}$ availability, we found that the number of fungicide application events was the most important predictor of hyphal $P$ transfer in cropland soil (Fig. 3.). A recent study found that the abundance of AMF is negatively linked to the amount of pesticide residues in agricultural soils, and certain pesticide residues could be detected even decades after their last application ${ }^{76}$. This indicates that adverse effects of fungicides on AMF might be long-lasting, corresponding to observations by Pánková et al. (2018)77, who showed that AMF infection rates of plants were reduced up to five years after the application of fungicides in a grassland site. These earlier studies focused on AMF abundance, whereas our results add a functional component to this debate and indicate that fungicide use in real agricultural contexts suppress AMF functioning.

Given the great variety of amounts and compounds of the applied fungicide products (Supplementary Table S1), it is remarkable that the number of fungicide application events used as rough indicator in this study could capture the adverse effects posed by fungicide use on AMF. Although fungicides are applied to combat fungal diseases such as mildew and rusts, they often have non-target effects on other fungi, including beneficial AMF. Detrimental effects of various fungicides have repeatedly been reported for AMF biomass, spore density, root colonization, and alkaline phosphatase activity in internal and external hyphae ${ }^{78-82}$. The negative effects of some fungicides on AMF have also been used in the past to assess the importance of AMF for plant community structure and diversity in grasslands (e.g., ${ }^{83,84}$ ). However, the close links between fungicide application rate and AMF functioning in a wide range of field soils observed here have not been reported before. It further indicates that modern agricultural practices including the use of fungicides hamper the natural ability of soils to provide crops with nutrients. Consequently, farmers may need to apply more phosphorus to compensate for reduced $\mathrm{P}$ availability. Future studies under controlled conditions in the field now need to specifically test to which extent fungicides suppress the ability of AMF to support crop growth and test whether such effects are persistent. Our results also call for reconsidering the design of agricultural systems to be able to make full use of the potential of AMF-symbiosis for plant nutrition. This could be achieved by, for example, the use of fungal disease resistant crop varieties to reduce the need for fungicides. Aside from that, applying agroecological methods, such as crop diversification, can be a promising way to reduce disease pressure ${ }^{4}$ while at the same time promoting AMF richness ${ }^{85}$, which might also link to the observed connection between crop diversity and hyphal P transfer in this study (Fig. 3B).

Implications for plant nutrition

Although ${ }^{33} \mathrm{P}$ uptake was not positively linked with higher total $\mathrm{P}$ uptake or plant growth, our observations indicate that hyphal mediated $\mathrm{P}$ uptake compensated for the lower available P levels in the grassland 
soils. This assumption is further supported by a positive connection between the plant N:P ratio and hyphal $\mathrm{P}$ transfer in grassland soils. This implies that when plant $\mathrm{P}$ demand in grassland is high and plant productivity is limited by $\mathrm{P}$ (e.g., plants with high N:P ratio), AMF supply additional $\mathrm{P}$ to the plant. Under such conditions, plants may also allocate more carbon to the AMF symbiosis to support the symbiosis ${ }^{86}$. However, this trend could not be confirmed in the cropland soils where no link between $N: P$ ratio and hyphal $\mathrm{P}$ uptake was found, possibly indicating a dysfunctional symbiosis in croplands.

Verbruggen et al. (2015) argued that the selective loss of AMF communities connected to soils with high $\mathrm{N}: P$ ratios might leave cropland fields with AMF of reduced symbiotic quality. While we agree that this could be the case for a multitude of fields with high soil N:P ratios in this study, the relatively large range of soil N:P ratios in both land use systems suggests that this is not the only mechanisms at play. The observed inability of putatively P-limited plants to acquire P through AMF hyphal activity in cropland soils provides further evidence that AMF are heavily affected by crop management, inhibiting their potential contribution to plant $\mathrm{P}$ nutrition in current cropping systems.

\section{Conclusion}

Despite the wide range of different environmental conditions along the surveyed gradient, the results show that the capacity of AMF to support plant $P$ nutrition is impaired in European croplands, particularly by the use of fungicides. Thus, we emphasize that there is a need to reconsider the design of agricultural systems to be able to make full use of the natural potential of AMF-symbiosis for a sustainable crop production.

\section{Declarations}

\section{Author contributions}

M.v.d.H., S.H., F.T.M., L.P. and M.C.R. designed the study and obtained research funding. A.E., G.G., S.B., C.H., E.K., D.S.P., S.R., A.Sa., F.D., P.G.P. and A.Sp. contributed to data collection and analysis. J.J. and E.F. supported the design and execution of the greenhouse experiment. A.E., conducted data analysis. A.E., G.G., M.v.d.H. and J.J. were involved in the interpretation of results. A.E., G.G and M.v.d.H. drafted the manuscript, with significant contributions to the writing from all co-authors. All authors commented on and approved the final manuscript.

\section{Acknowledgements}

We are thankful to all the farmers and farm managers for allowing us to sample their fields and for completing our detailed questionnaires. We also thank Alain Held, Andrea Bonvicini, Dr. Laurie Schönholzer, Monica Macsai, Dr. Federica Tamburini, Dr. Hannes Gamper, Susanne Müller, Diane Bürge, Martin Zuber, Shuai Zhao, Vincent Somerville, Andri Brugger, Orlando Scholz, David Bugmann, Robin Heiz, Benjamin Seitz, and Miriam Roser for help with field work, the design and execution of the greenhouse 
experiment and lab analyses, and Dr. Julian Helfenstein for valuable feedback on the manuscript. The Digging Deeper project was funded through the 2015-2016 BiodivERsA COFUND call for research proposals, with the national funders Swiss National Science Foundation (grant 31BD30-172466), Deutsche Forschungsgemeinschaft (317895346), Swedish Research Council Formas (contract 20160194), Ministerio de Economía y Competitividad (Digging_Deeper, Ref. PCIN-2016-028) and Agence Nationale de la Recherche (ANR, France; grant ANR-16-EBI3-0004-01).

\section{Data availability}

The data that support the findings of this study are available here: $10.6084 / \mathrm{m} 9$.figshare. 15134328 .

\section{Code availability}

The code used to analyze the data is available here: $10.6084 / \mathrm{m} 9$. figshare.15134670.

\section{References}

1. Foley, J. A. et al. Solutions for a cultivated planet. Nature 478, 337-342 (2011).

2. Tilman, D., Balzer, C., Hill, J. \& Befort, B. L. Global food demand and the sustainable intensification of agriculture. 108, 20260-20264 (2011).

3. Bender, S. F., Wagg, C. \& van der Heijden, M. G. A. An Underground Revolution: Biodiversity and Soil Ecological Engineering for Agricultural Sustainability. Trends Ecol. Evol. 31, 440-452 (2016).

4. Tamburini, G. et al. Agricultural diversification promotes multiple ecosystem services without compromising yield. Sci. Adv. 6, (2020).

5. Smith, S. \& Read, D. Mycorrhizal Symbiosis. Mycorrhizal Symbiosis (Elsevier, 2008). doi:10.1016/B978-0-12-370526-6.X5001-6

6. Soudzilovskaia, N. A. et al. Global patterns of plant root colonization intensity by mycorrhizal fungi explained by climate and soil chemistry. Glob. Ecol. Biogeogr. 24, 371-382 (2015).

7. Pearson, J. N. \& Jakobsen, I. The relative contribution of hyphae and roots to phosphorus uptake by arbuscular mycorrhizal plants, measured by dual labelling with 32P and 33P. New Phytol. 124, 489494 (1993).

8. Van Der Heijden, M. G. A., Bardgett, R. D. \& Van Straalen, N. M. The unseen majority: Soil microbes as drivers of plant diversity and productivity in terrestrial ecosystems. Ecol. Lett. 11, 296-310 (2008).

9. Bennett, E. M., Carpenter, S. R. \& Caraco, N. F. Human impact on erodable phosphorus and eutrophication: A global perspective. Bioscience 51, 227-234 (2001).

10. Smith, V. H. \& Schindler, D. W. Eutrophication science: where do we go from here? Trends Ecol. Evol. 24, 201-207 (2009). 
11. Bender, S. F. \& van der Heijden, M. G. A. Soil biota enhance agricultural sustainability by improving crop yield, nutrient uptake and reducing nitrogen leaching losses. J. Appl. Ecol. 52, 228-239 (2015).

12. Rodriguez, A. \& Sanders, I. R. The role of community and population ecology in applying mycorrhizal fungi for improved food security. ISME Journa/ 9, 1053-1061 (2015).

13. Oviatt, P. \& Rillig, M. C. Mycorrhizal technologies for an agriculture of the middle. Plants, People, Planet ppp3.10177 (2020). doi:10.1002/ppp3.10177

14. Ryan, M. H. \& Graham, J. H. Little evidence that farmers should consider abundance or diversity of arbuscular mycorrhizal fungi when managing crops. New Phytologist 220, 1092-1107 (2018).

15. Rillig, M. C. et al. Why farmers should manage the arbuscular mycorrhizal symbiosis. New Phytol. 222, 1171-1175 (2019).

16. Zhang, S., Lehmann, A., Zheng, W., You, Z. \& Rillig, M. C. Arbuscular mycorrhizal fungi increase grain yields: a meta-analysis. New Phytol. 222, 543-555 (2019).

17. Thirkell, T. J., Charters, M. D., Elliott, A. J., Sait, S. M. \& Field, K. J. Are mycorrhizal fungi our sustainable saviours? Considerations for achieving food security. J. Ecol. 105, 921-929 (2017).

18. Davison, J. et al. Global assessment of arbuscular mycorrhizal fungus diversity reveals very low endemism. Science (80-). 349, 970-973 (2015).

19. Pringle, A. \& Bever, J. D. Analogous effects of arbuscular mycorrhizal fungi in the laboratory and a North Carolina field. New Phytol. 180, 162-175 (2008).

20. Francis, R. \& Read, D. J. Mutualism and antagonism in the mycorrhizal symbiosis, with special reference to impacts on plant community structure. Can. J. Bot. 73, 1301-1309 (1995).

21. Lehmann, A., Barto, E. K., Powell, J. R. \& Rillig, M. C. Mycorrhizal responsiveness trends in annual crop plants and their wild relatives -a meta-analysis on studies from 1981 to 2010 . Plant Soil 355, 231-250 (2012).

22. Martín-Robles, N. et al. Impacts of domestication on the arbuscular mycorrhizal symbiosis of $27 \mathrm{crop}$ species. New Phytol. 218, 322-334 (2018).

23. Oehl, F. et al. Impact of Land Use Intensity on the Species Diversity of Arbuscular Mycorrhizal Fungi in Agroecosystems of Central Europe. Appl. Environ. Microbiol. 69, 2816-2824 (2003).

24. Xiang, D. et al. Land use influences arbuscular mycorrhizal fungal communities in the farmingpastoral ecotone of northern China. New Phytol. 204, 968-978 (2014).

25. Bainard, L. D. et al. Plant communities and soil properties mediate agricultural land use impacts on arbuscular mycorrhizal fungi in the Mixed Prairie ecoregion of the North American Great Plains. Agric. Ecosyst. Environ. 249, 187-195 (2017).

26. Eurostat. LUCAS 2018 Technical reference document C3 Classification (Land cover \& Land use). 2018, 98 (2018).

27. Fick, S. E. \& Hijmans, R. J. WorldClim 2: new 1-km spatial resolution climate surfaces for global land areas. Int. J. Climatol. 37, 4302-4315 (2017). 
28. Trabucco, A. \& Zomer, R. Global Aridity Index and Potential Evapotranspiration (ET0) Climate Database v2. figshare (2019). doi:https://doi.org/10.6084/m9.figshare.7504448.v3

29. García-Palacios, P., Gross, N., Gaitán, J. \& Maestre, F. T. Climate mediates the biodiversity-ecosystem stability relationship globally. Proc. Natl. Acad. Sci. U. S. A. 115, 8400-8405 (2018).

30. Berdugo, M. et al. Global ecosystem thresholds driven by aridity. Science (80-). 367, 787-790 (2020).

31. Sinnott, R. W. Virtues of the Haversine. Sky Telescope 68.2, 158 (1984).

32. Garland, G. et al. Crop cover is more important than rotational diversity for soil multifunctionality and cereal yields in European cropping systems. Nat. Food 2, 28-37 (2021).

33. Berry, D., Mahfoudh, K. Ben, Wagner, M. \& Loy, A. Barcoded Primers Used in Multiplex Amplicon Pyrosequencing Bias Amplification † 'Barcode-tagged' PCR primers used for multiplex amplicon sequencing generate a thus-far-overlooked amplification bias that produces variable terminal restriction fragment length polymorphism (T-RFLP) and pyrosequencing data from the same environmental DNA template. We propose a simple two-step PCR ap-proach that increases reproducibility and consistently recovers higher genetic diversity in pyrosequencing libraries. Appl. Environ. Microbiol. 77, 7846-7849 (2011).

34. Gardes, M., White, T. J., Fortin, J. A., Bruns, T. D. \& Taylor, J. W. Identification of indigenous and introduced symbiotic fungi in ectomycorrhizae by amplification of nuclear and mitochondrial ribosomal DNA. Can. J. Bot. 69, 180-190 (1991).

35. Gardes, M. \& Bruns, T. D. ITS primers with enhanced specificity for basidiomycetes - application to the identification of mycorrhizae and rusts. Mol. Ecol. 2, 113-118 (1993).

36. Fiore-Donno, A. M. et al. New barcoded primers for efficient retrieval of cercozoan sequences in highthroughput environmental diversity surveys, with emphasis on worldwide biological soil crusts. Mol. Ecol. Resour. 18, 229-239 (2018).

37. Schweiger, P. F., Thingstrup, I. \& Jakobsen, I. Comparison of two test systems for measuring plant phosphorus uptake via arbuscular mycorrhizal fungi. Mycorrhiza 8, 207-213 (1999).

38. Svenningsen, N. B. et al. Suppression of the activity of arbuscular mycorrhizal fungi by the soil microbiota. ISME J. 12, 1296-1307 (2018).

39. Helfenstein, J., Jegminat, J., McLaren, T. I. \& Frossard, E. Soil solution phosphorus turnover: Derivation, interpretation, and insights from a global compilation of isotope exchange kinetic studies. Biogeosciences 15, 105-114 (2018).

40. Scheublin, T. R., Ridgway, K. P., Young, J. P. W. \& van der Heijden, M. G. A. Nonlegumes, Legumes, and Root Nodules Harbor Different Arbuscular Mycorrhizal Fungal Communities. Appl. Environ. Microbiol. 70, 6240-6246 (2004).

41. Rodushkin, I., Ruth, T. \& Huhtasaari, Å. Comparison of two digestion methods for elemental determinations in plant material by ICP techniques. Anal. Chim. Acta 378, 191-200 (1999).

42. Ohno, T. \& Zibilske, L. M. Determination of Low Concentrations of Phosphorus in Soil Extracts Using Malachite Green. Soil Sci. Soc. Am. J. 55, 892-895 (1991). 
43. Thonar, C., Schnepf, A., Frossard, E., Roose, T. \& Jansa, J. Traits related to differences in function among three arbuscular mycorrhizal fungi. Plant Soil 339, 231-245 (2011).

44. R Core team. R: A Language and Environment for Statistical Computing. (2013).

45. Calcagno, V. Model Selection and Multimodel Inference Made Easy [R package glmulti version 1.0.8]. (2020).

46. Cade, B. S. Model averaging and muddled multimodel inferences. Ecology (2015). doi:10.1890/141639.1

47. Barton, K. MuMIn: Multi-Model Inference. R package version 1.43.17. Version 1, 18 (2020).

48. Model Selection and Multimodel Inference. (Springer New York, 2002). doi:10.1007/b97636

49. Oehl, F. et al. Soil type and land use intensity determine the composition of arbuscular mycorrhizal fungal communities. Soil Biol. Biochem. 42, 724-738 (2010).

50. De Vries, F. T. et al. Soil food web properties explain ecosystem services across European land use systems. Proc. Natl. Acad. Sci. U. S. A. 110, 14296-14301 (2013).

51. Verbruggen, E., Xiang, D., Chen, B., Xu, T. \& Rillig, M. C. Mycorrhizal fungi associated with high soil $\mathrm{N}: \mathrm{P}$ ratios are more likely to be lost upon conversion from grasslands to arable agriculture. Soil Biol. Biochem. 86, 1-4 (2015).

52. Balami, S., Vašutová, M., Godbold, D., Kotas, P. \& Cudlín, P. Soil fungal communities across land use types. IForest 13, 548-558 (2020).

53. Öpik, M., Mari, M., Liira, J. \& Zobel, M. Composition of root-colonizing arbuscular mycorrhizal fungal communities in different ecosystems around the globe. J. Ecol. 94, 778-790 (2006).

54. Rillig, M. C. et al. The role of multiple global change factors in driving soil functions and microbial biodiversity. Science 366, 886-890 (2019).

55. Jansa, J. et al. Diversity and structure of AMF communities as affected by tillage in a temperate soil. Mycorrhiza 12, 225-234 (2002).

56. van Groenigen, K. J. et al. Abundance, production and stabilization of microbial biomass under conventional and reduced tillage. Soil Biol. Biochem. 42, 48-55 (2010).

57. Simpson, R. J. et al. Strategies and agronomic interventions to improve the phosphorus-use efficiency of farming systems. Plant and Soil 349, (2011).

58. Nagy, R., Drissner, D., Amrhein, N., Jakobsen, I. \& Bucher, M. Erratum: Mycorrhizal phosphate uptake pathway in tomato is phosphorusrepressible and transcriptionally regulated (New Phytologist (2009) 181 (950-959)). New Phytol. 184, 1029 (2009).

59. Smith, S. E., Jakobsen, I., Grønlund, M. \& Smith, F. A. Roles of arbuscular mycorrhizas in plant phosphorus nutrition: Interactions between pathways of phosphorus uptake in arbuscular mycorrhizal roots have important implications for understanding and manipulating plant phosphorus acquisition. Plant Physiol. 156, 1050-1057 (2011).

60. Williams, A., Manoharan, L., Rosenstock, N. P., Olsson, P. A. \& Hedlund, K. Long-term agricultural fertilization alters arbuscular mycorrhizal fungal community composition and barley (Hordeum 
vulgare) mycorrhizal carbon and phosphorus exchange. New Phytol. 213, 874-885 (2017).

61. Meyer, A. et al. Different Land Use Intensities in Grassland Ecosystems Drive Ecology of Microbial Communities Involved in Nitrogen Turnover in Soil. PLoS One 8, e73536 (2013).

62. Tsiafouli, M. A. et al. Intensive agriculture reduces soil biodiversity across Europe. Glob. Chang. Biol. 21, 973-985 (2015).

63. Tardy, V. et al. Shifts in microbial diversity through land use intensity as drivers of carbon mineralization in soil. Soil Biol. Biochem. 90, 204-213 (2015).

64. Leake, J. et al. Networks of power and influence: The role of mycorrhizal mycelium in controlling plant communities and agroecosystem functioning. Can. J. Bot. 82, 1016-1045 (2004).

65. Sawers, R. J. H. et al. Phosphorus acquisition efficiency in arbuscular mycorrhizal maize is correlated with the abundance of root-external hyphae and the accumulation of transcripts encoding PHT1 phosphate transporters. New Phytol. 214, 632-643 (2017).

66. Cavagnaro, T. R., Smith, F. A., Smith, S. E. \& Jakobsen, I. Functional diversity in arbuscular mycorrhizas: exploitation of soil patches with different phosphate enrichment differs among fungal species. Plant, Cell and Environment 28, (2005).

67. Jakobsen, I., Gazey, C. \& Abbott, L. K. Phosphate transport by communities of arbuscular mycorrhizal fungi in intact soil cores. New Phytol. 149, 95-103 (2001).

68. Van Aarle, I. M., Olsson, P. A. \& Söderström, B. Arbuscular mycorrhizal fungi respond to the substrate $\mathrm{pH}$ of their extraradical mycelium by altered growth and root colonization. New Phytol. 155, 173-182 (2002).

69. Staddon, P. L. et al. Mycorrhizal fungal abundance is affected by long-term climatic manipulations in the field. Glob. Chang. Biol. 9, 186-194 (2003).

70. Weber, S. E. et al. Responses of arbuscular mycorrhizal fungi to multiple coinciding global change drivers. Fungal Ecol. 40, 62-71 (2019).

71. Peat, H. J. \& Fitter, A. H. The distribution of arbuscular mycorrhizas in the British flora. New Phytol. 125, 845-854 (1993).

72. Cruz-Paredes, C. et al. Suppression of arbuscular mycorrhizal fungal activity in a diverse collection of non-cultivated soils. FEMS Microbiol. Ecol. 95, (2019).

73. Jansa, J., Erb, A., Oberholzer, H.-R., Šmilauer, P. \& Egli, S. Soil and geography are more important determinants of indigenous arbuscular mycorrhizal communities than management practices in Swiss agricultural soils. Mol. Ecol. 23, 2118-2135 (2014).

74. Davison, J. et al. Temperature and $\mathrm{pH}$ define the realised niche space of arbuscular mycorrhizal fungi. New Phytol. 231, 763-776 (2021).

75. Yang, H. et al. Changes in soil organic carbon, total nitrogen, and abundance of arbuscular mycorrhizal fungi along a large-scale aridity gradient. Catena 87, 70-77 (2011).

76. Riedo, J. et al. Widespread Occurrence of Pesticides in Organically Managed Agricultural Soils-the Ghost of a Conventional Agricultural Past? Environ. Sci. Technol. (2021). 
doi:10.1021/acs.est.0c06405

77. Pánková, H., Dostálek, T., Vazačová, K. \& Münzbergová, Z. Slow recovery of arbuscular mycorrhizal fungi and plant community after fungicide application: An eight-year experiment. J. Veg. Sci. 29, 695-703 (2018).

78. Ipsilantis, I., Samourelis, C. \& Karpouzas, D. G. The impact of biological pesticides on arbuscular mycorrhizal fungi. Soil Biol. Biochem. (2012). doi:10.1016/j.soilbio.2011.08.007

79. Buysens, C., Dupré de Boulois, H. \& Declerck, S. Do fungicides used to control Rhizoctonia solani impact the non-target arbuscular mycorrhizal fungus Rhizophagus irregularis? Mycorrhiza (2015). doi:10.1007/s00572-014-0610-7

80. Lekberg, Y., Wagner, V., Rummel, A., McLeod, M. \& Ramsey, P. W. Strong indirect herbicide effects on mycorrhizal associations through plant community shifts and secondary invasions. Ecol. Appl. 27, 2359-2368 (2017).

81. Hage-Ahmed, K., Rosner, K. \& Steinkellner, S. Arbuscular mycorrhizal fungi and their response to pesticides. Pest Management Science 75, 583-590 (2019).

82. Kjøller, R. \& Rosendahl, S. Effects of fungicides on arbuscular mycorrhizal fungi: differential responses in alkaline phosphatase activity of external and internal hyphae. Biol. Fertil. Soils 31, 361365 (2000).

83. Gange, A. C., Brown, V. K. \& Sinclair, G. S. Vesicular-Arbuscular Mycorrhizal Fungi: A Determinant of Plant Community Structure in Early Succession. Funct. Ecol. 7, 616 (1993).

84. Hartnett, D. C. \& Wilson, G. W. T. The role of mycorrhizas in plant community structure and dynamics: Lessons from grasslands. Plant Soil 244, 319-331 (2002).

85. Guzman, A. et al. Crop diversity enriches arbuscular mycorrhizal fungal communities in an intensive agricultural landscape. (2021). doi:10.1111/nph.17306

86. Johnson, N. C. Resource stoichiometry elucidates the structure and function of arbuscular mycorrhizas across scales. New Phytol. 185, 631-647 (2010).

\section{Figures}




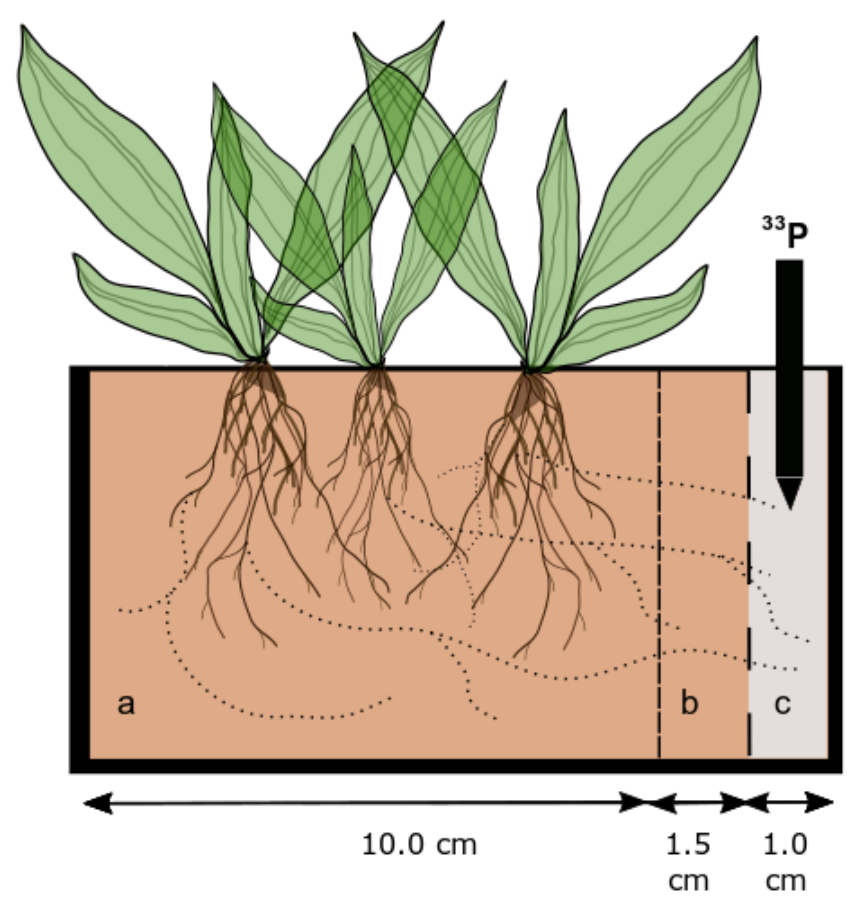

\section{Figure 1}

Experimental set-up using Plantago lanceolata as a phytometer in pots containing three compartments. The plant zone (compartment $a$ ) and the buffer zone (compartment b) were filled with the collected field soils. The compartment c contained a standardized, sterilized soil which was injected with the tracer 33P. Compartment a was separated from b using a $40 \mu \mathrm{m}$ mesh (narrow dashed line), restricting root 
penetration. The mash barrier between $b$ and c compartments had a pore size of $500 \mu \mathrm{m}$ (wide dashed line).
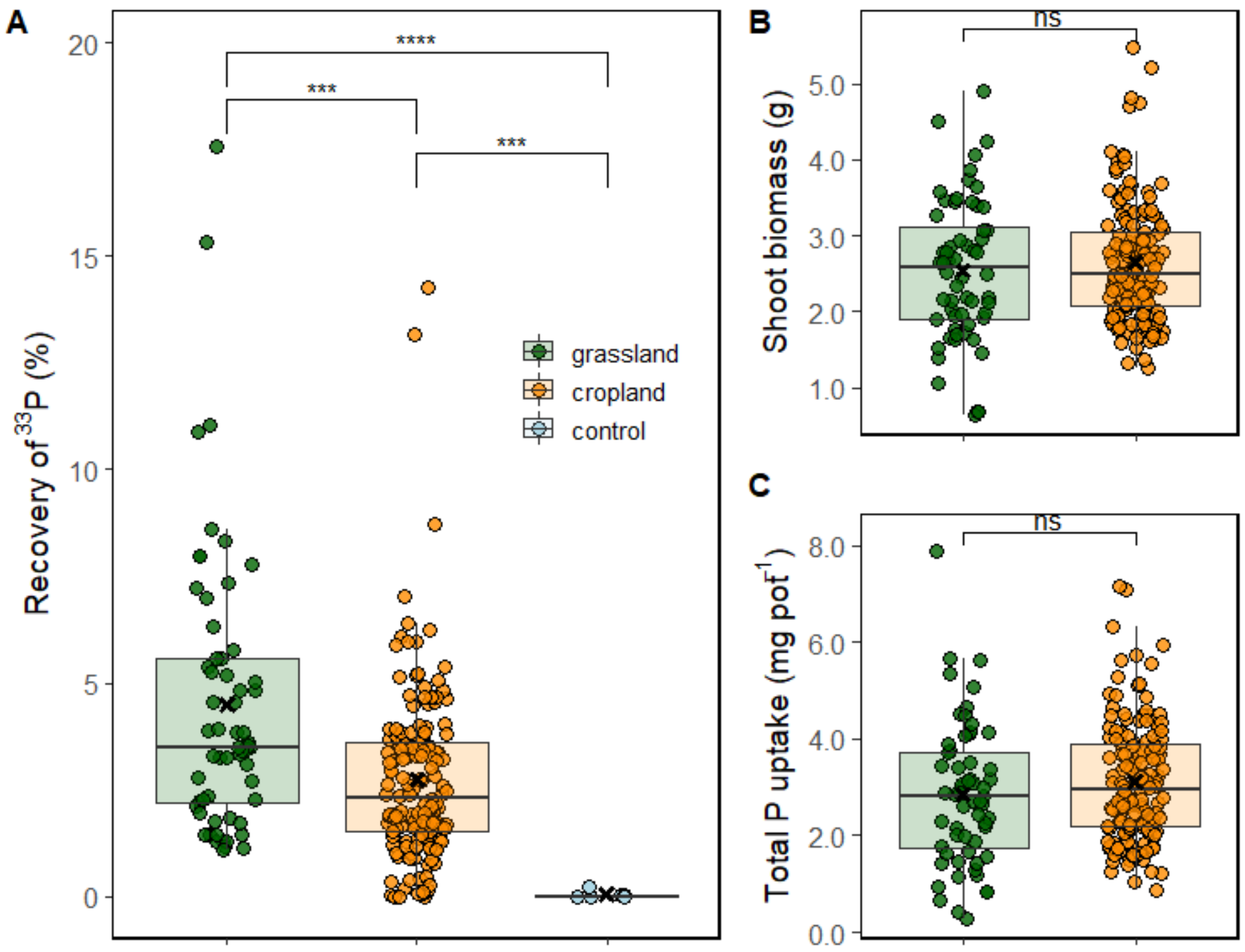

\section{Figure 2}

Recovery of 33P in the shoot material of Plantago lanceolata plants grown in grassland (green), cropland (orange) and sterilized control soils (blue) (A). The low 33P recovery in sterilized control soils confirm that 33P uptake corresponds to hyphal activity in the field soils. Shoot biomass (B) and total P uptake per pot (C) in the grassland vs. cropland soils. Bold lines mark the median and " $x$ " the mean values. ${ }^{* \star}$ indicates a significant difference between land use systems ( $p<0.001$, Wilcoxon rank test), "ns" no significant difference. 


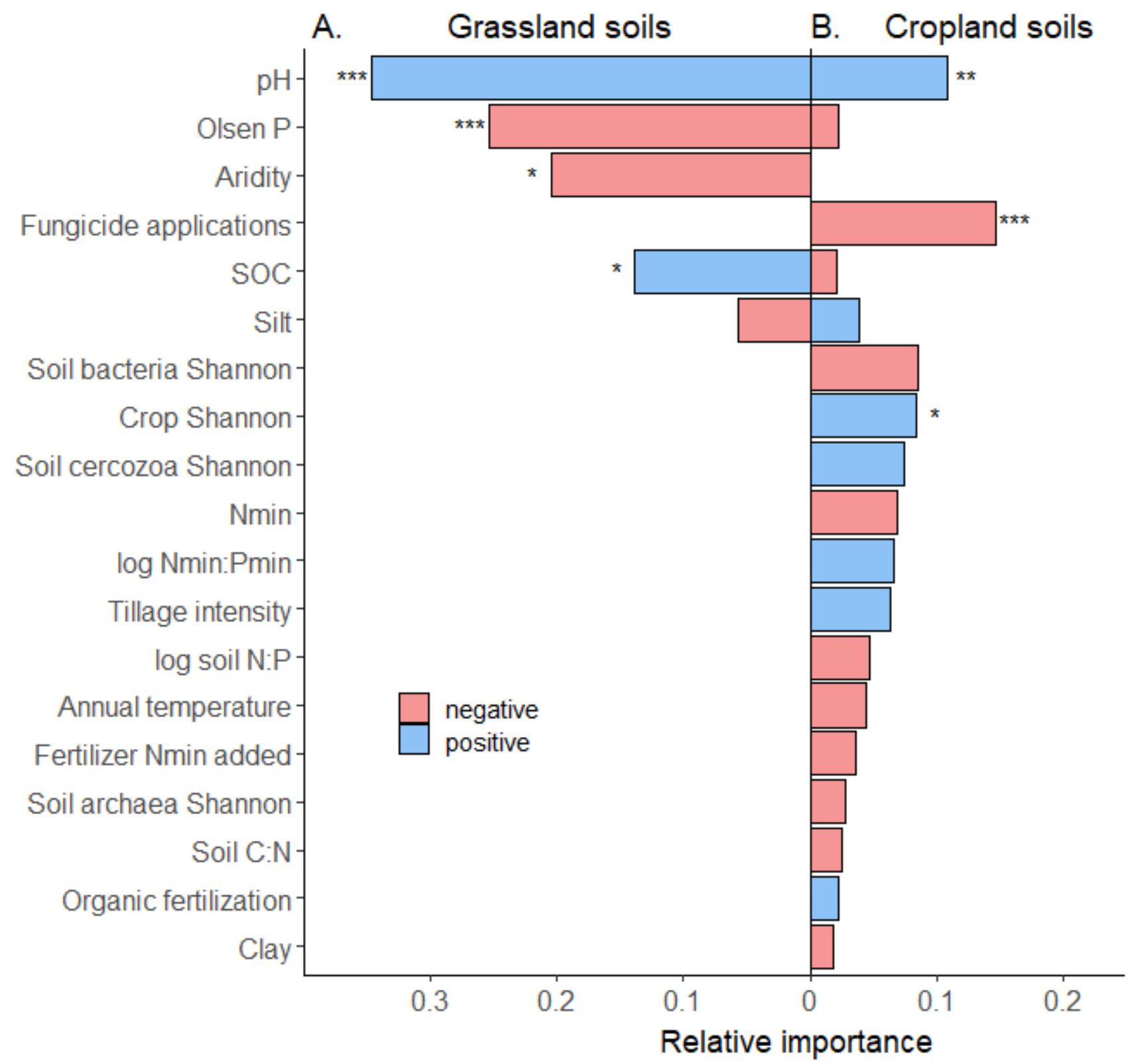

Figure 3

Relative importance of predictors for hyphal $\mathrm{P}$ uptake, measured as 33P recovery in plant shoots based on a multi-model inference approach, in grassland $(A)$ versus cropland soils (B). Note that the crop management predictors were used only in the cropland model. Predictors were ordered according to their total importance (i.e., sum of both land use types). Negative and positive correlations are shown in red and blue, respectively. Asterisks indicate a significant correlation at $p<0.001$ ( $\left.\left.{ }^{\star * \star}\right), p<0.01{ }^{(* \star}\right)$ and $p<0.05$ $(*)$. 

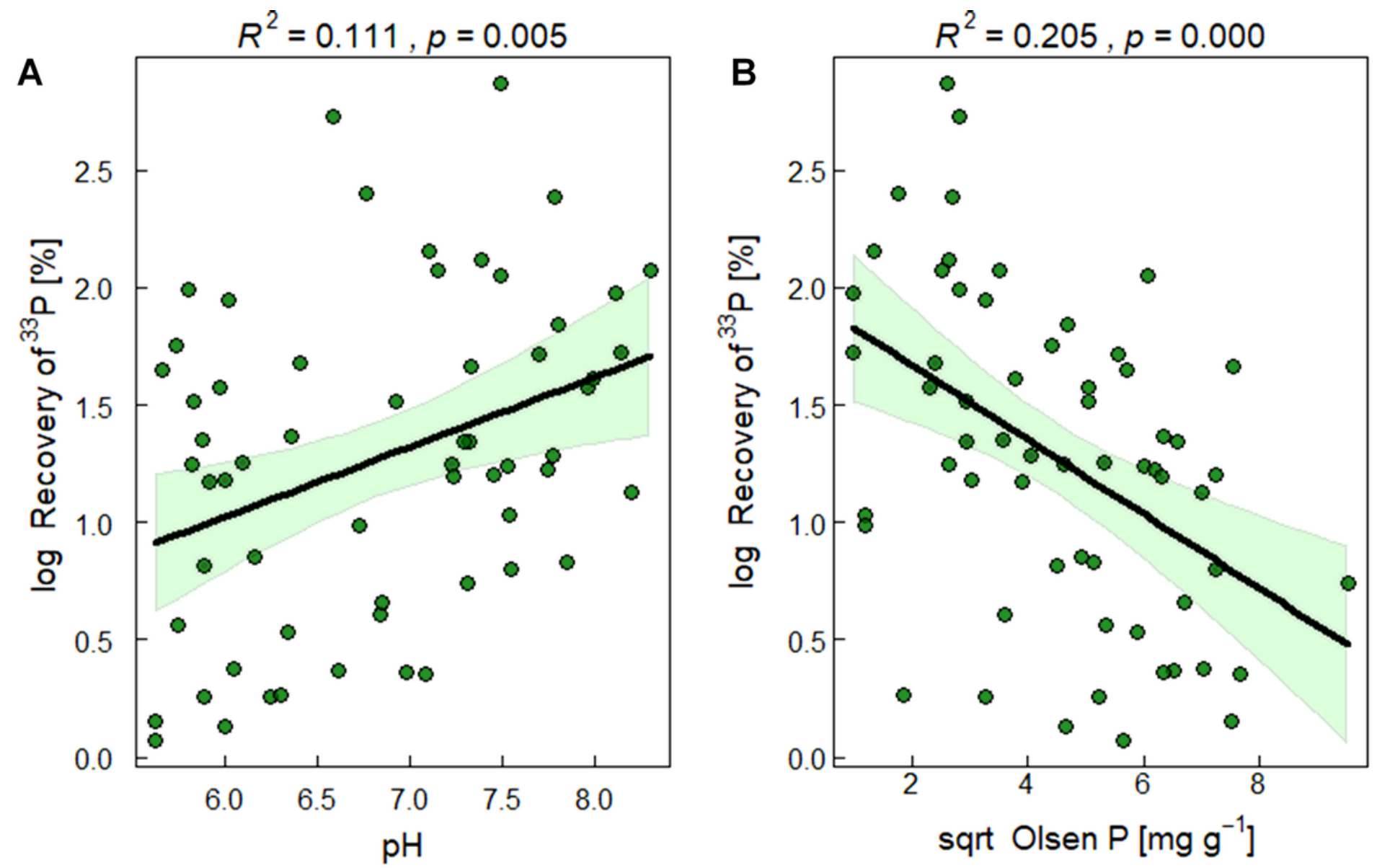

Figure 4

Correlation of 33P recovery with soil pH (A), and available soil P $(B)$ in the grassland sites. The green polygon frames the upper and lower confidence level (0.95). 


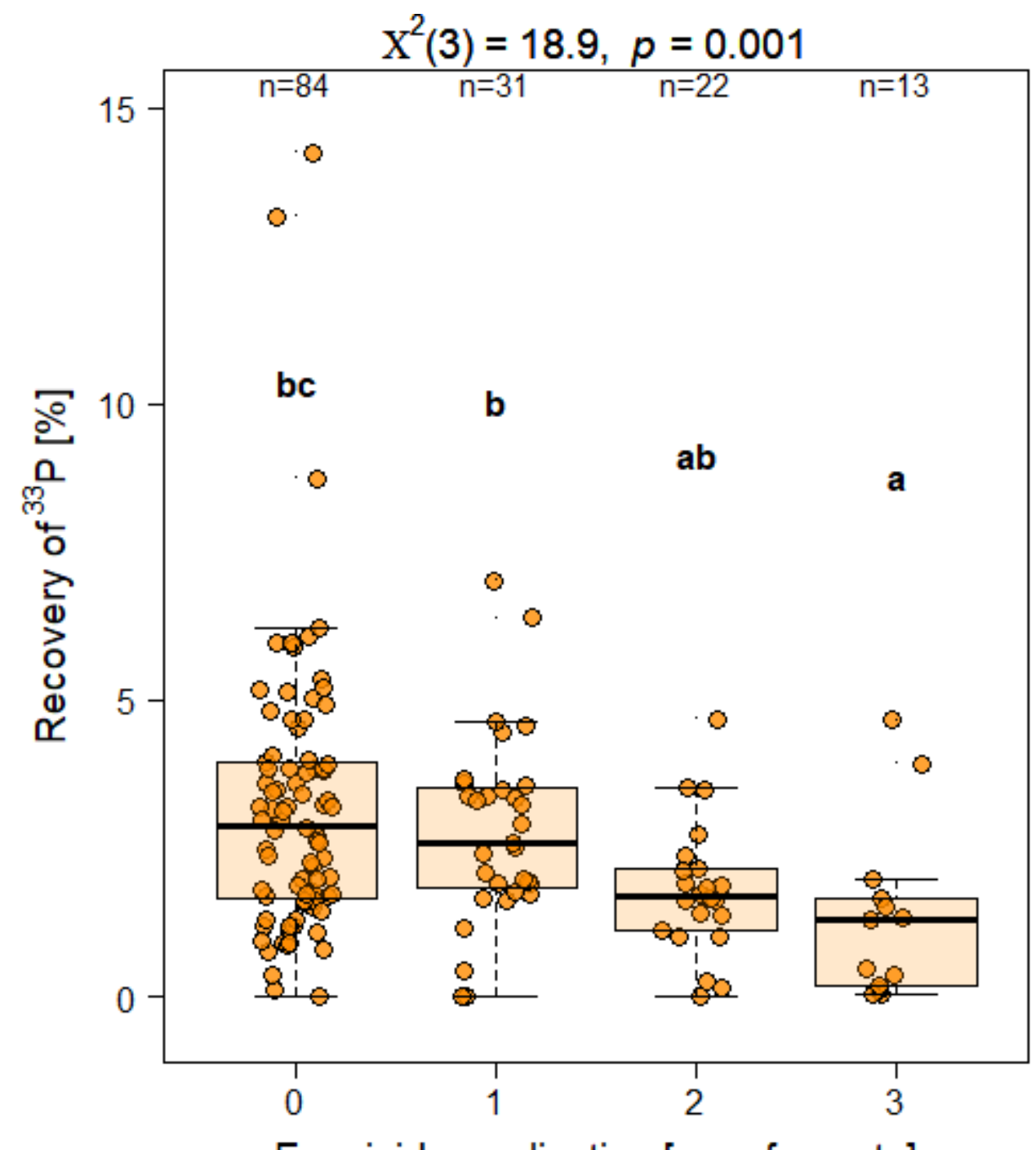

Fungicide application [no. of events]

Figure 5

Differences in 33P recovery induced by an increasing number of fungicide application events in the croplands were examined using a Kruskal-Wallis rank test where X2 represents the model fit with the degrees of freedom in brackets. Significant differences between the number of applications are indicated with different letters.

\section{Supplementary Files}

This is a list of supplementary files associated with this preprint. Click to download.

- EdlingeretalSupplemenatry.docx

- EdlingeretalSuppltables2.xIsx

- EdlingeretalSuppltables3.xIsx 